\title{
Diclofenac in hyaluronic acid gel: an alternative treatment for actinic cheilitis
}

\author{
Giana da Silveira LIMA', Gabriela Ferrari da SILVA², Ana Paula Neutzling GOMES ${ }^{3}$, Lenita Maria Aver de ARAÚJO³, \\ Fernanda Gonçalves SALUM ${ }^{4}$ \\ 1- DDS, MSc, PhD student, Department of Operative Dentistry, Federal University of Pelotas, Pelotas, RS, Brazil.
2- DDS Graduate student, Department of Operative Dentistry, Federal University of Pelotas, Pelotas, RS, Brazil.
3- DDS, MSc, PhD in Oral Pathology, Associate Professor, Department of Semiology and Clinic, Center for Diagnosis of Oral Diseases, Federal University
of Pelotas, Pelotas, RS, Brazil.
4- DDS, PhD in Oral Medicine, Oral Medicine and Oral Maxillofacial Cancer Prevention Unit, São Lucas Hospital, Pontifical Catholic University of Rio Grande
do Sul, Porto Alegre, RS, Brazil.
}

Corresponding address: Fernanda Gonçalves Salum - Pontifícia Universidade Católica do Rio Grande do Sul - PUCRS - Hospital São Lucas - Av. Ipiranga, 6690 - Sala 231 - $2^{\circ}$ andar - 90610-000 - Porto Alegre - RS - Brazil - Phone/Fax: +55 51 3320-3254 - e-mail: fesalum@terra.com.br

Received: March 5, 2009 - Modification: September 7, 2009 - Accepted: October 22, 2009

\section{ABSTRACT}

bjective: Actinic cheilitis (AC) is a precancerous lesion of the lip vermillion caused by prolonged exposure to ultraviolet light. The aim of this study was to evaluate the effect of $3 \%$ diclofenac in $2.5 \%$ hyaluronic acid gel in the treatment of AC. Methods: Thirty-four patients with chronic AC were treated twice a day with topical diclofenac during a period of 30 to 180 days. The individuals were followed up every 15 days by means of clinical examination and digital photographic documentation. Results: Of the 27 patients that completed the study, $12(44 \%)$ showed complete remission of the whitish plaques and exfoliative areas, and $15(56 \%)$ had partial remission of the clinical picture of cheilitis. The latter group was submitted to excision of the leukoplakic areas which diagnosis varied from mild to moderate epithelial dysplasia. Conclusions: The results suggest a promising role for diclofenac in hyaluronic acid gel in the treatment of AC. This treatment has the advantages of not being invasive and showing few side effects.

Key words: Diclofenac. Hyaluronic acid. Cheilitis. Actinic rays. Oral leukoplakia.

\section{INTRODUCTION}

Actinic cheilitis (AC), also called actinic cheilosis or solar cheilitis, is a potentially malignant condition of the lip vermillion caused by long-time exposure to ultraviolet light. This lesion affects mostly the lower lip and is more frequent in individuals with fair skin, males and those who are regularly in the sun such as farm workers and fishermen ${ }^{5}$. In the south region of Brazil, due to the tropical climate and the European descent of large part of the population, this lesion assumes great importance.

There are two clinical forms of AC: acute and chronic. The acute form is more common in young individuals and occurs after excessive exposure to the ultraviolet light, while the chronic form is a cumulative and irreversible alteration. In chronic AC, the lip appears parched and atrophic, with dyschromic areas, white or gray plaques and recurrent erosions ${ }^{7,20}$. The lesion is usually asymptomatic, but can in some cases be accompanied by a burning sensation, numbness and pain.
The main objectives of treatment of chronic AC are to prevent the development of squamous cell carcinoma, improve the aesthetic picture and diminish the inconvenience caused by lip erosions, crusts and roughness. There are various therapeutic modalities with the aim of removing the altered epithelium of these lesions such as the topical application of 5-fluorouracil, trichloroacetic acid, imiquimod and retinoids. Other treatments include surgical excision with cold scalpel (vermillionectomy), vaporization with $\mathrm{CO}_{2}$ or Er:YAG laser, cryosurgery, electrodissection and photodynamic therapy with aminolevulinic acid $^{1,11,15,16}$. These treatments are very destructive and frequently cause considerable discomfort to the patients, which has stimulated the development of effective and economically viable alternatives for the treatment of AC. Diclofenac in hyaluronic acid gel has been employed in the topical treatment of actinic keratoses with satisfactory results and well-tolerated side effects by the majority of the patients ${ }^{12,14,19}$. The present study was conducted with the aim of evaluating by means of a clinical 
follow-up the effect of $3 \%$ diclofenac in $2.5 \%$ hyaluronic acid gel in the treatment chronic actinic cheilitis.

\section{MATERIAL AND METHODS}

This study was approved by the Research Ethics Committee of the Dental School of the Federal University of Pelotas, Brazil. Thirty-four patients who had been diagnosed with chronic actinic cheilitis, seen at the Center for Diagnosis of Oral Diseases of the Federal University of Pelotas, Brazil, without noteworthy systemic alterations, were enrolled for this study. The patients exhibited on physical examination areas of leukoplakia (whitish plaques), spotting and/or exfoliation of the lip vermillion. The inclusion criteria were: presence of white plaques, dyschromic and or exfoliative areas in the lower lip. Patients with erosion, ulcerated areas and plaques with irregular surface were not included in the study (exclusion criteria). The objectives of the study were explained to the individuals, and afterwards, they signed an informed consent form. The patients were then submitted to anamnesis and physical oral examination. Digital photographic documentation was taken for each case to record the extent of labial alterations. These alterations were classified as: Grade I: presence of dyschromic areas; Grade II: presence of exfoliative areas; Grade III: presence of whitish plaque(s); and Grade IV: combination of two or more of these alterations.
The treatment protocol consisted of the topical application of $3 \%$ diclofenac in $2.5 \%$ hyaluronic acid gel on the lip vermillion, twice a day (morning and night), after oral hygiene. The patients were instructed to not eat or drink for one hour after the application and to use lip sunscreen with SPF 15 during all day long. The individuals were followed up every 15 days, and the period of treatment was determined by the response and necessity of each case, ranging from 30 to 180 days.

An image record was taken at the initial visit and each follow-up visit to evaluate the results. The evaluation was performed by two calibrated examiners on the basis of information of the patient's chart, physical examination and observation of the photographic documentation.

\section{RESULTS}

Twenty-seven patients completed the treatment. All the subjects were Caucasian, with a predominance of fair skin, and most of them practiced professional activities involving ultraviolet light exposure. The lesion was more common among men, with a gender ratio of $8: 1$ and mean age of $58(\mathrm{SD} \pm 12)$ years old. The patients were asymptomatic, although seven individuals complained about aesthetic discomfort.

Figure 4 presents the result obtained in each case, the grade of actinic cheilitis of the patients treated and the duration of the therapy. Approximately $78 \%$ of the patients exhibited

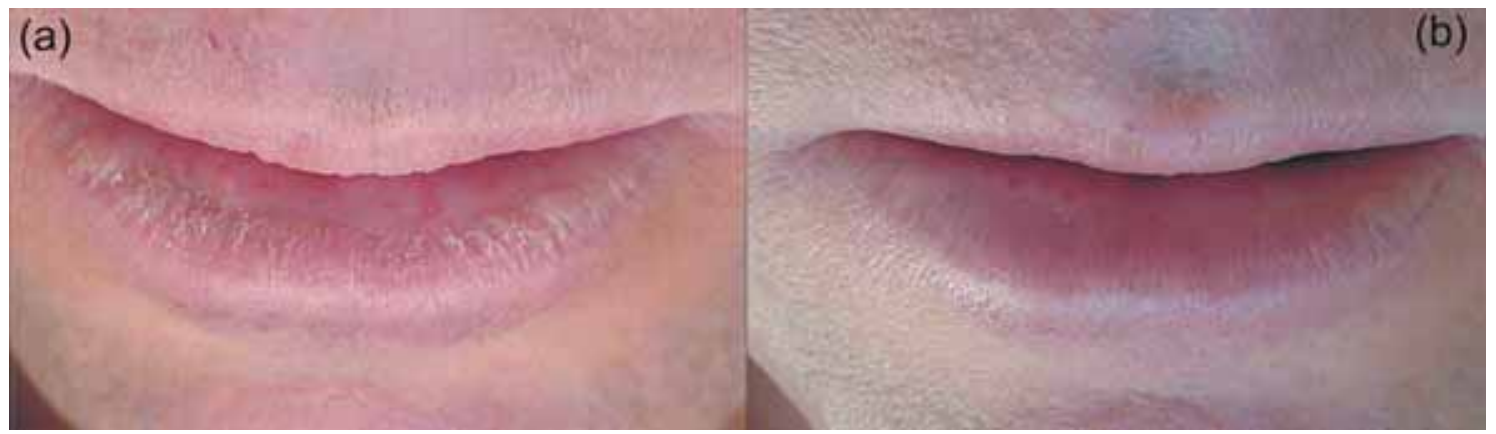

Figure 1- Actinic cheilitis grade II, lower lip showed exfoliative areas (a), which exhibited total remission (b) after 60 days of topical application of diclofenac

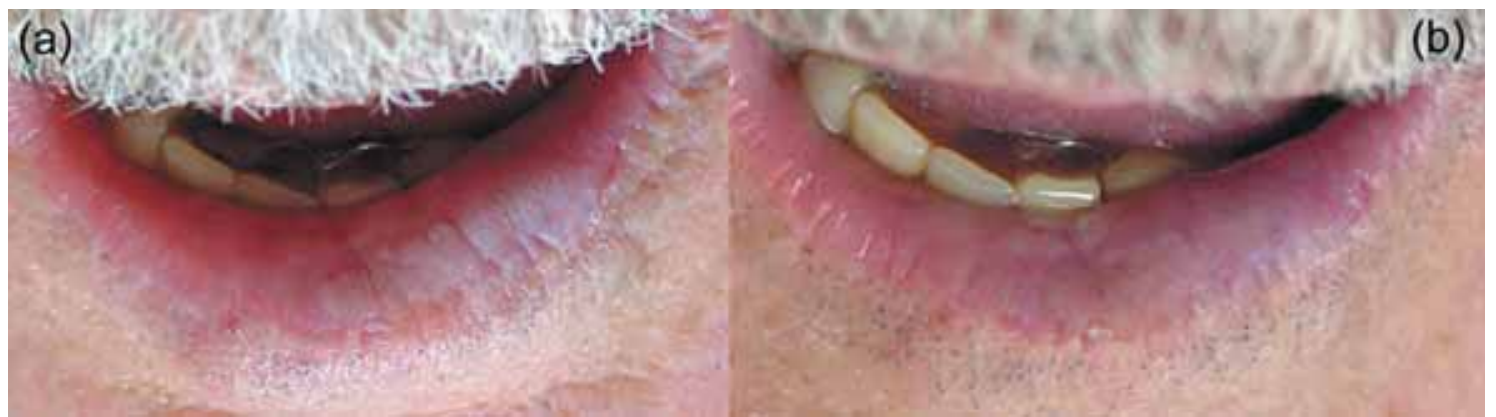

Figure 2- Actinic cheilitis grade IV with leukoplakic and spotting areas (a). Lesion showed total remission of the leukoplakic area, however, spotting areas continued to be present (b) 


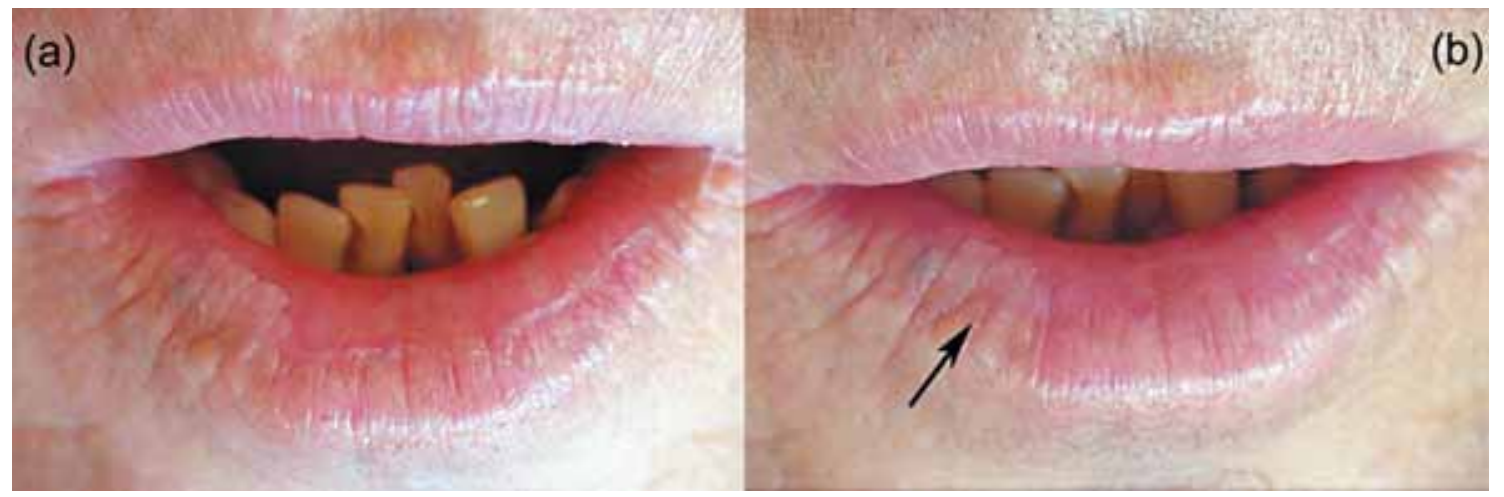

Figure 3- Actinic cheilitis grade IV, before (a) and after (b) 180 days of diclofenac topical application. Lip showed partial remission of cheilitis, with decrease of the thickness of the leukoplakic areas. The whitish plaque (arrow) was later excised

\begin{tabular}{|c|c|c|c|c|c|}
\hline \multirow[b]{2}{*}{ CASE } & \multirow[b]{2}{*}{ GENDER } & \multirow[b]{2}{*}{ AGE } & \multirow[b]{2}{*}{ GRADE } & \multicolumn{2}{|c|}{ TREATMENT } \\
\hline & & & & Period (day) & Result \\
\hline 1 & M & 67 & IV & 30 & \\
\hline 2 & $\mathrm{M}$ & 76 & IV & 30 & \\
\hline 3 & $\mathrm{~F}$ & 63 & IV & 30 & \\
\hline 4 & $\mathrm{~F}$ & 38 & IV & 30 & \\
\hline 5 & $M$ & 76 & IV & 60 & \\
\hline 6 & $M$ & 65 & II & 60 & \\
\hline 7 & $M$ & 66 & III & 60 & REMISSION \\
\hline 8 & $M$ & 76 & IV & 120 & \\
\hline 9 & $M$ & 41 & II & 180 & \\
\hline 10 & $M$ & 75 & III & 180 & \\
\hline 11 & $M$ & 61 & IV & 180 & \\
\hline 12 & $M$ & 47 & IV & 180 & \\
\hline 13 & $M$ & 45 & III & 180 & \\
\hline 14 & $M$ & 45 & III & 180 & \\
\hline 15 & $M$ & 45 & IV & 180 & \\
\hline 16 & $M$ & 52 & IV & 180 & \\
\hline 17 & $M$ & 67 & IV & 180 & \\
\hline 18 & $M$ & 53 & IV & 180 & \\
\hline 19 & $M$ & 78 & IV & 180 & \\
\hline 20 & $\mathrm{~F}$ & 45 & IV & 180 & PARTIAL \\
\hline 21 & $M$ & 64 & IV & 180 & REMISSION \\
\hline 22 & $M$ & 56 & IV & 180 & \\
\hline 23 & $M$ & 48 & IV & 180 & \\
\hline 24 & $M$ & 67 & IV & 180 & \\
\hline 25 & $M$ & 61 & IV & 180 & \\
\hline 26 & $M$ & 49 & IV & 180 & \\
\hline 27 & $M$ & 43 & IV & 180 & \\
\hline
\end{tabular}

Figure 4- Gender, age and grade of actinic cheilitis of the 27 patients who completed the therapy, as well as, period and results obtained with the topical application of diclofenac

chronic AC classified as grade IV, $15 \%$ grade III and $7 \%$ grade II. In $48 \%$ of the cases, all of the extent of the lower lip appeared affected. In the other cases, the areas affected varied in extension and continuity. The presence of whitish plaques was evident in 25 patients, while 23 showed exfoliative areas and 24 spotting of the lip.

Improvement of the lesions was observed in all the patients, with diminution of the thickness of the leukoplakic areas, disappearance of scaling areas and greater hydration, besides more uniform coloration. Of the 27 patients who completed the study, $12(44 \%)$ showed total remission of the plaque and exfoliative areas present at the start of treatment (Figures 1A, 1B, 2A, 2B). However, dyschromic regions continued to be present. Fifteen patients $(56 \%)$ exhibited significant improvement of $A C$ but without complete resolution of the condition (Figures 3A, 3B), with the persistence of whitish plaques, which were later excised. The diagnosis of these biopsied lesions varied from mild to moderate epithelial dysplasia.

The drug utilized was well tolerated by the patients, but in two cases, treatment was discontinued due to the development of an allergic picture characterized by edema and intense erythema, associated with a burning sensation at the site of drug application. Five patients discontinued treatment for personal reasons unrelated to the study. All the individuals who concluded the study remained on follow-up for at least 1 year and routinely used lip sunscreen.

\section{DISCUSSION}

Actinic cheilitis is a lesion of the lip vermillion, analogous to actinic keratoses, which has been treated by surgical procedures and topical drugs, some with a cytotoxic effect and the potential to cause tissue destruction ${ }^{1,11,16}$. The topical action of diclofenac in a hyaluronic acid vehicle has been investigated for the treatment of actinic keratoses, showing promising results and less intense adverse effects in comparison with other drugs such as 5 -fluorouracil ${ }^{17}$. In the present study, the action of diclofenac was investigated in the treatment of chronic actinic cheilitis, which showed leukoplakic, dyschromic and exfoliative areas. Complete or partial remission of the clinical picture of the lesions was obtained in all the cases, a finding that corroborates with the studies of Ulrich, et al. ${ }^{18}$ (2007) and Nelson, et al. ${ }^{10}$ (2007), who also utilized diclofenac in the treatment of $A C$, in samples of six and 19 individuals, respectively. Ulrich, et al. ${ }^{18}$ (2007) utilized this drug for 6 weeks and Nelson, et al. ${ }^{10}$ (2007) for 90 days.

In the present study, the period of treatment was 
based on the clinical response of each case, where the maximum period was established as 180 days. The complete resolution of the clinical presentation determined the suspension of the therapy and was obtained in as little as 30 days of treatment. The variation in the speed of response to diclofenac was also observed in the topical treatment of solar keratoses $4,13,14,19$ and is associated mainly with inherent factors of individuals. Additionally, the response to treatment depends on the disposition and motivation of the patients to achieve a positive outcome, as well as the amount of medication used in each application. In the present study, the amount of substance applied varied based on the interpretation by the individuals of the instructions supplied by the investigator.

Diclofenac is a non-steroidal anti-inflammatory agent (NSAID) whose mechanism of action is not completely understood. Its possible antineoplasic effect is being investigated, because it induces apoptosis by inhibiting cyclooxygenases (COX-1 and $\mathrm{COX}-2$ ), which are involved in the metabolism of arachidonic acid and are superexpressed in various epithelial tumors ${ }^{3}$. The hypothesis proposed is that NSAIDs, by inhibiting the metabolism of arachidonic acid, impede the potent tumorigenic effects of its metabolites. Such effects include the conversion of pro-oncogenes to oncogenes, inhibition of immunologic vigilance, inhibition of apoptosis, stimulation of angiogenesis and increase in invasiveness of tumor cells ${ }^{8}$. Therefore, diclofenac can be effective in the treatment as well as the prevention of epithelial lesions related to actinic radiation.

Hyaluronic acid, the vehicle in which diclofenac is delivered, has been widely utilized in the cosmetics industry because of its moisturizing properties. This polysaccharide was chosen primarily with the aim of allowing the accumulation of diclofenac in the epidermis, prolonging its half-life at the site of action $^{2,9}$. In addition to these effects, Wolf, et al. ${ }^{19}$ (2001) suggested that the hyaluronic acid gel may have intrinsic activity, increasing the efficacy of the treatment.

The lip vermilion is an anatomic site in which treatment can be difficult due to the risk of permanent scars and susceptibility to irritation ${ }^{10}$. However, the application of diclofenac in hyaluronic acid gel did not cause the development of erosive or ulcerated areas on the lips. Of the 29 patients who effectively underwent treatment, only two showed adverse effects that determined their exclusion from the study. These local reactions including pruritis, erythema and/or burning sensation were observed in some cases, and were tolerated by the patients. These adverse reactions have also been described by other authors who studied the use of diclofenac for the treatment of keratoses as well as actinic cheilitis ${ }^{10,14,18}$.

The risk of relapse after the treatment instituted is unknown. However, the patients in this study were followed-up for more than a year and those who had a complete remission of the clinical picture of cheilitis showed no signs of recurrence. The patients who had a partial remission were submitted to excisional biopsy of the whitish plaques and displayed no signs of progression of the lesion. Meanwhile, the majority of the patients studied continue to be exposed to ultraviolet light, since they maintained their outdoor occupational activities. The follow-up of these individuals and their awareness with respect to precautions and preventive measures with the use of sunscreen and hats are essential.

The results of the present study are in accordance with the literature regarding the epidemiologic profile and clinical characteristics of actinic cheilitis ${ }^{6,7,10}$. For didactic purposes, in this study, cheilitis were classified according to severity as grade I through grade IV. Twenty-one out the 27 patients who were treated showed chronic AC grade IV. However, due to the small number of patients with cheilitis grade II and III, it was not possible to carry out statistical comparisons of the results obtained for the different lesion grades.

\section{CONCLUSION}

As with the treatment of actinic keratoses, 3\% diclofenac in $2.5 \%$ hyaluronic acid gel showed promising results and good tolerability in the treatment of AC, indicating a treatment modality adequate for this precursor lesion. In addition, this treatment has the advantages of not being invasive, having low cost and showing few side effects and good aesthetic results. There is a need for randomized studies to investigate the action of this drug; however, as AC is a precancerous lesion, the comparison of the action of diclofenac in placebo-controlled studies is impracticable. All the other available treatment modalities that are established for this disease show a high potential for tissue damage, which makes it difficult to compare their effects with those of diclofenac in hyaluronic acid gel in randomized clinical trials.

\section{REFERENCES}

1- Berking C, Herzinger T, Flaig MJ, Brenner M, Borelli C, Degitz $\mathrm{K}$. The efficacy of photodynamic therapy in actinic cheilitis of the lower lip: a prospective study of 15 patients. Dermatol Surg. 2007;33:825-30.

2- Brown MB, Hanpanitcharoen M, Martin GP. An in vitro investigation into the effect of glycosaminoglycans on the skin partitioning and deposition of NSAIDs. Int J Pharm. 2001;225:113-21.

3- Fecker LF, Stockfleth E, Nindl I, Ulrich C, Forschner T, Eberle J. The role of apoptosis in the therapy and prophylaxis of epithelial tumours by nonsteroidal anti-inflammatory drugs (NSAIDs). Br J Dermatol. 2007;156(Suppl 3):25-33.

4- Gebauer K, Brown P, Varigos G. Topical diclofenac in hyaluronan gel for the treatment of solar keratoses. Australas J Dermatol. 2003; 44:40-3.

5- Huber MA, Terezhalmy GT. The patient with actinic cheilitis. Gen Dent. 2006;54:274-82. 
6- Kaugars GE, Pillion T, Svirsky JA, Page DG, Burns JC, Abbey LM. Actinic cheilitis: a review of 152 cases. Oral Surg Oral Med Oral Pathol Oral Radiol Endod. 1999;88:181-6.

7- Markopoulos A, Albanidou-Farmaki E, Kayavis I. Actinic cheilitis: clinical and pathologic characteristics in 65 cases. Oral Dis. $2004 ; 10: 212-6$.

8- Masferrer JL, Leahy KM, Koki AT, Zweifel BS, Settle SL, Woerner BM, et al. Antiangiogenic and antitumor activities of cyclooxygenase-2 inhibitors. Cancer Res. 2000;60:1306-11.

9- Moore AR, Willoughby DA. Hyaluronan as a drug delivery system for diclofenac: a hypothesis for mode of action. Int J Tissue React. 1995;17:153-6.

10- Nelson CG, Spencer J, Nelson CG Jr. A single-arm, open-label efficacy and tolerability study of diclofenac sodium $3 \% \mathrm{gel}$ for the treatment of actinic keratosis of the upper and lower lip. J Drugs Dermatol. 2007;6:712-7.

11- Orenstein A, Goldan O, Weissman O, Winkler E, Haik J. A new modality in the treatment of actinic cheilitis using the Er:YAG laser. J Cosmet Laser Ther. 2007;9:23-5.

12- Pirard D, Vereecken, Mélot C, Heenen M. Three percent diclofenac in $2.5 \%$ hyaluronan gel in the treatment of actinic keratoses: a meta-analysis of the recent studies. Arch Dermatol Res. 2005;297:185-9.

13- Rivers JK, Arlette J, Shear N, Guenther L, Carey W, Poulin Y. Topical treatment of actinic keratoses with $3.0 \%$ diclofenac in 2.5\% hyaluronan gel. $\mathrm{Br}$ ] Dermatol. 2002;146:94-100.
14- Rivers JK, McLean DI. An open study to assess the efficacy and safety of topical $3 \%$ diclofenac in a $2.5 \%$ hyaluronic acid gel for the treatment of actinic keratoses. Arch Dermatol. 1997; 133:1239-42.

15- Robinson JK. Actinic cheilitis. A prospective study comparing four treatment methods. Arch Otolaryngol Head Neck Surg. 1989;115:848-52.

16- Smith KJ, Germain M, Yeager J, Skelton H. Topical 5\% imiquimod for the therapy of actinic cheilitis. J Am Acad Dermatol. 2002;47:497-501.

17- Smith SR, Morhenn VB, Piacquadio DJ. Bilateral comparison of the efficacy and tolerability of $3 \%$ diclofenac sodium gel and $5 \% 5$-fluorouracil cream in the treatment of actinic keratoses of the face and scalp. J Drugs Dermatol. 2006;5:156-9.

18- Ulrich C, Forschner T, Ulrich M, Stockfleth E, Sterry W, Termeer $\mathrm{C}$. Management of actinic cheilitis using diclofenac $3 \%$ gel: a report of six cases. Br J Dermatol. 2007;156(Suppl 3):436.

19- Wolf JE Jr, Taylor JR, Tschen E, Kang S. Topical 3.0\% diclofenac in $2.5 \%$ hyaluronan gel in the treatment of actinic keratoses. Int J Dermatol. 2001;40:709-13.

20- Wright K, Dufresne R. Actinic cheilitis. Dermatol Surg. $1998 ; 24: 490-1$. 